\title{
DESIGN AND OPTIMISATION OF 2-D STATIC SOLAR CONCENTRATOR
}

\author{
Imhamed M. Saleh ${ }^{*}$, E.M. Elmabrouk ${ }^{2}$, and F. A. Taher ${ }^{2}$ \\ ${ }^{1}$ Department of Mechanical Engineering, Faculty of Engineering, Sirte University \\ Sirte P.O.Box 674, Libya \\ ${ }^{2}$ Department of Chemical Engineering, Faculty of Engineering, Sirte University \\ Sirte P.O.Box 674, Libya \\ Email: isa6@su.edu.ly
}

\begin{abstract}
A non-imaging solar concentrator system of reflecting surfaces redirect the solar radiation from source to target (receiver). This work is focused on a 2-D elliptical hyperboloid geometric design of static solar collectors, though many design concepts and procedures for 2-D static solar collector is discussed in this paper. Based on the general equation for a solar concentrator, parameters vary slightly to determine the optical efficiency. 2-D MATLAB code is written to obtain the different shapes of the concentrator. The results of 2-D hyperboloid concentrator (2-DHC) has been reported. The optical efficiency, effective concentration ratio, receiver major axis and concentrator height have been investigated through ray trace analysis. The optimisation of the concentrator profile and geometry is also carried out, based on the geometrical concentration ratio. The maximum optical efficiency is found to be $51 \%$ and the maximum acceptance angle of $\pm 60^{\circ}$ was achieved.
\end{abstract}

$$
\begin{aligned}
& \text { تحليل البارومترت الهندسية لمركزات الطاقة الشمسية الثابتة ثنائية الأبعاد } \\
& \text { امحمد مفتاح صالح*', المبروكك محمد المبرولك 2 و فرج علي الطاهر } 2
\end{aligned}
$$

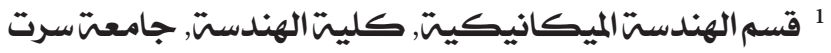

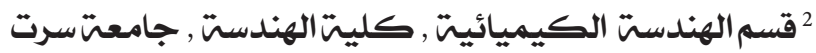

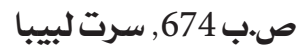

\section{* Corresponding author}

DOI: $10.51646 /$ jsesd.v10i1.98

This is an open access article under the CC BY-NC license (http://Attribution-NonCommercial 4.0 (CC BY-NC 4.0)). 


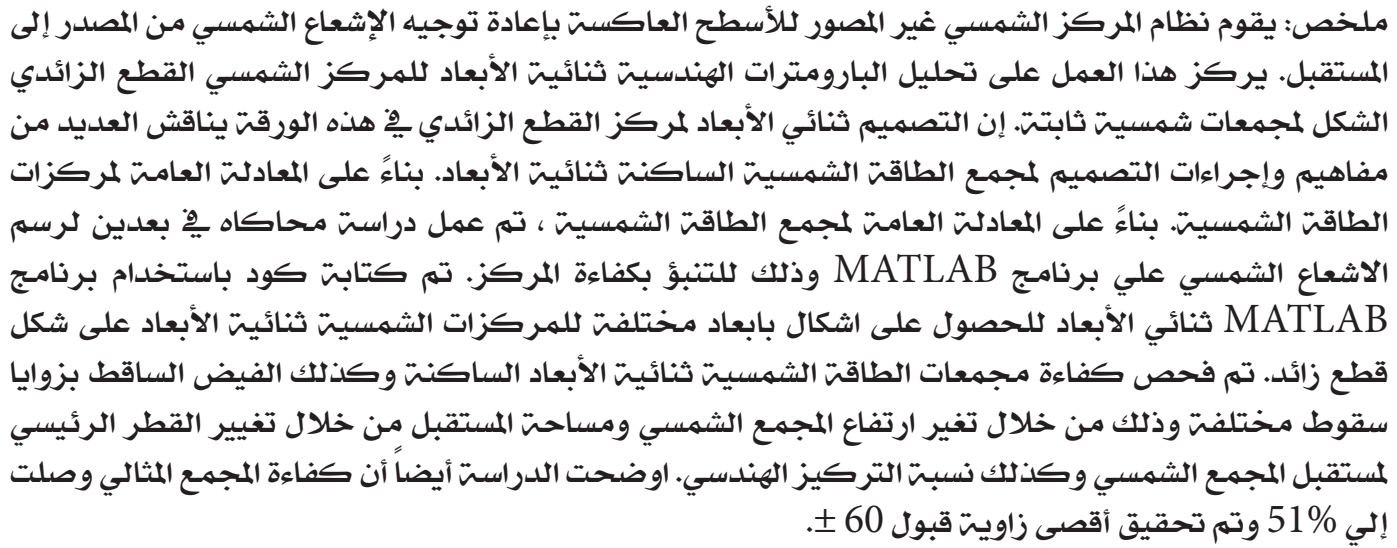

Keywords: solar concentrator, optimisation, optical efficiency, parabolic concentrators (CPCs), optical performance.

\section{INTRODUCTION}

A new approach of non-imaging optics was introduced in 1960 by Kritchman [1]. Compared to imaging concentrators, a non-imaging system has a wider acceptance angle. Due to this, the system has the capability of approaching the thermodynamic limit of the concentration ratio and is capable of collecting the solar radiation for eight hours per day [2]. Furthermore, the diffuse radiation is also captured, which is lost in imaging systems. During the past few decades, several designs of non-imaging concentrators have been developed. Compound parabolic concentrators (CPCs) and trumpets (hyperbola) are the most common nonimaging systems. Without a tracking system, the maximum concentration ratio for an imaging concentrator with secondary reflector was found to be 3 or 4 [3]. Winston [2] showed that a concentration ratio of 9.6 could be achieved with a trough-CPC system. They achieved a concentration ratio exceeding the sine law of concentration. A comparison between the characteristics of parabolic and Fresnel concentrator systems and CPCs was presented by Rabl [4]. The continuous development of non-imaging systems has led to the development of optic techniques to analyses the non-imaging systems

Ali et al. [8] investigated the optical performance of a 2-D and 3-D hyperboloid concentrator using ray tracing simulation code and inspected the best combination of the optical efficiency and acceptance angle to improve the overall performance of concentrator. Garcia-Botella [5] studied a 3-D asymmetric concentrators without rotational and translational symmetry based on photometric field theory and elliptic ray bundles for non-tracking solar applications. Senthilkumar [6] investigated the optical and thermal performance on horizontally segmented 3-D CPC. Sellami et al. [7] designed a novel 3-D static concentrator and evaluated the best combination of optical efficiency and acceptance angle. A good agreement between experimental measurements from a manufactured square elliptical hyperboloid and optical simulation results was observed. Ali et al. [8] evaluated the performance of a 3-D elliptical hyperboloid concentrator using ray tracing software and carried out the optimisation study of the profile and geometry to improve the overall performance of concentrator. The optical efficiency was found to be $28 \%$ for a concentration ratio of 20 '. Antonio [9] presented the optical simulation of solar PV concentrators using two inverse characterisation methods (inverse illumination, and inverse luminescence operating with electroluminescent light); And it was stated that the inverse illumination method enhances the simulation process. The ray coming through the aperture of the concentrator can reach the receiver directly or by one or two reflections. Some of the rays may escape after two or three reflections. Rays may be reflected one, two or more times before reaching the receiver [10]. 


\section{Optical Analysis of 2-D Hyperboloid Concentrator}

\subsection{2-D Hyperboloid Concentrator}

The acceptance angle is one of the important parameters for determination of optical efficiency. The angle subtends between the extreme rays of concentrator aperture and optical axis of the receiver is called half acceptance angle $(\varnothing / 2)$. For a fixed concentrator height $(0.4 \mathrm{~m})$ and receiver diameter $(0.2 \mathrm{~m})$, the 2-D hyperboloid curvature for different concentration ratio $\left(5^{\prime}, 10^{\prime}, 15^{\prime}, 20^{\prime}\right.$ and $\left.25^{\prime}\right)$ is obtained. The 2-D hyperboloid curvature for different concentration ratio is shown in figurel. It is clear that the aperture area of the concentrator of $5^{\prime}$ is five times higher than that of area of the receiver. As the concentration ratio increases, the half acceptance angle also increases. In order to see the variation of concentrator height on the acceptance angle, the concentrator height is varied for a fixed concentration ratio of $20^{\prime}$ and receiver diameter of $0.2 \mathrm{~m}$. The concentrator height is varied from $0.4 \mathrm{~m}$ to $1 \mathrm{~m}(0.4 \mathrm{~m}, 0.8 \mathrm{~m}, 1 \mathrm{~m})$. The 2-D hyperboloid concentrators of different height $(0.4 \mathrm{~m}, 0.8 \mathrm{~m}$ and $1 \mathrm{~m})$ are shown in figure 2. It is found that as the concentration ratio increases, the half acceptance angle also increases. In order to compare all the hyperboloid curvatures are superimposed. Ray tracing simulation were carried out to study the effect of change in the different optical parameters on the optical efficiency.

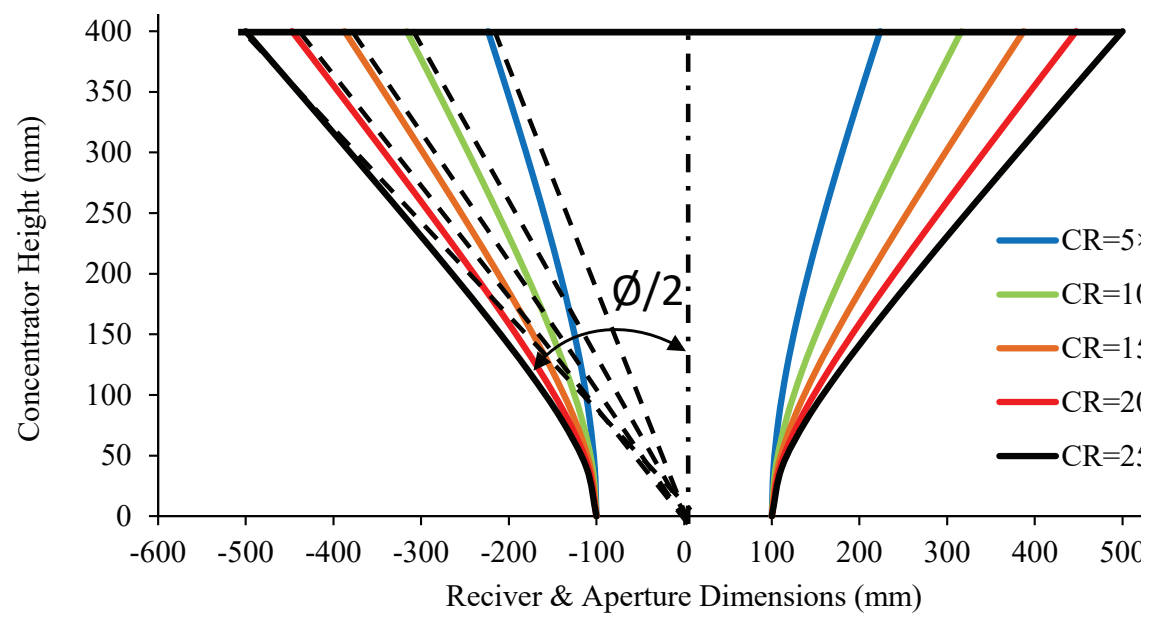

Figure 1: 2-D Hyperboloid Curvatures for Different Concentration Ratio

\subsection{Ray tracing Technique for Hyperboloid Concentrator}

In ray trace analysis, the sun rays are modeled to redirect the maximum fraction of incoming radiation onto the receiver diameter. The basic laws of optics (reflection) are used to model the behavior of the rays at the incident surface. In the ray trace analysis, the concentration ratio of $20 \times$ and the receiver diameter of $0.1 \mathrm{~m}$ are considered (located at the bottom of the concentrator), while The incident angle is varied from $0^{\circ}$ to $90^{\circ}$ in the anticlockwise direction. The sun rays are perpendicular to the collector aperture at $0^{\circ}$ (normal sun rays). At a $90^{\circ}$ incident angle, the sun rays are horizontal. Ray tracing analysis is carried out for different incidence angle $\left(0^{\circ}, 15^{\circ}, 30^{\circ}, 45^{\circ}\right.$ and $\left.60^{\circ}\right)$ and for different concentrator heights $(0.2 \mathrm{~m}, 0.4 \mathrm{~m}$ and $1 \mathrm{~m})$. Ray tracing diagrams for concentrator height of $0.4 \mathrm{~m}$ and $0.2 \mathrm{~m}$ for different incidence angles of $0^{\circ}, 15^{\circ}, 30^{\circ}, 45^{\circ}$ and $60^{\circ}$ are shown in figure 3. The ray tracing for concentrator height of $0.1 \mathrm{~m}$ for incidence angles of $0^{\circ}, 15^{\circ}$, $30^{\circ}$ and $45^{\circ}$ is shown in figure $\otimes 4$. 


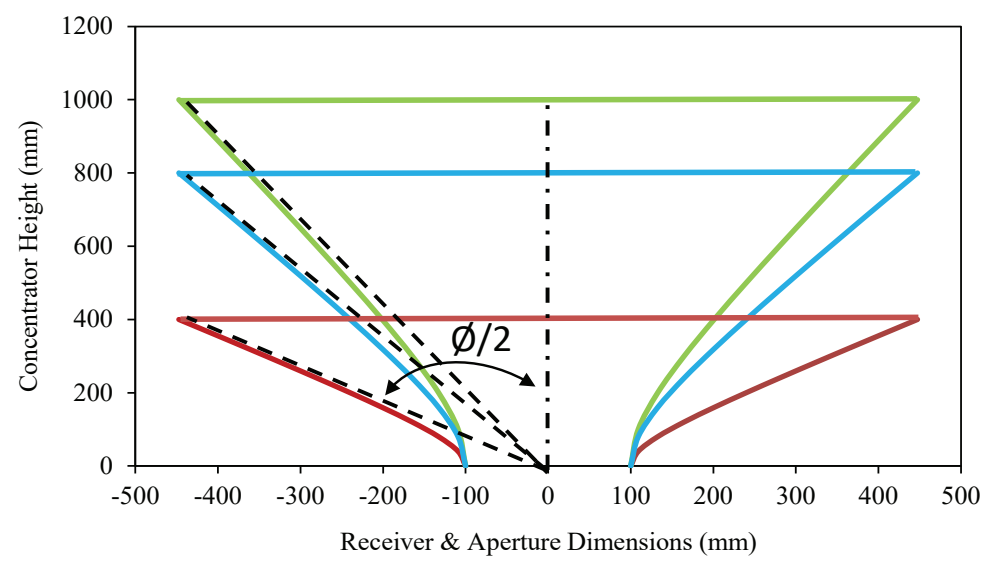

Figure 2: 2-D Hyperboloid Curvature for Different Concentrator Heights (0.4 m, 0.8 m, $1 \mathrm{~m})$
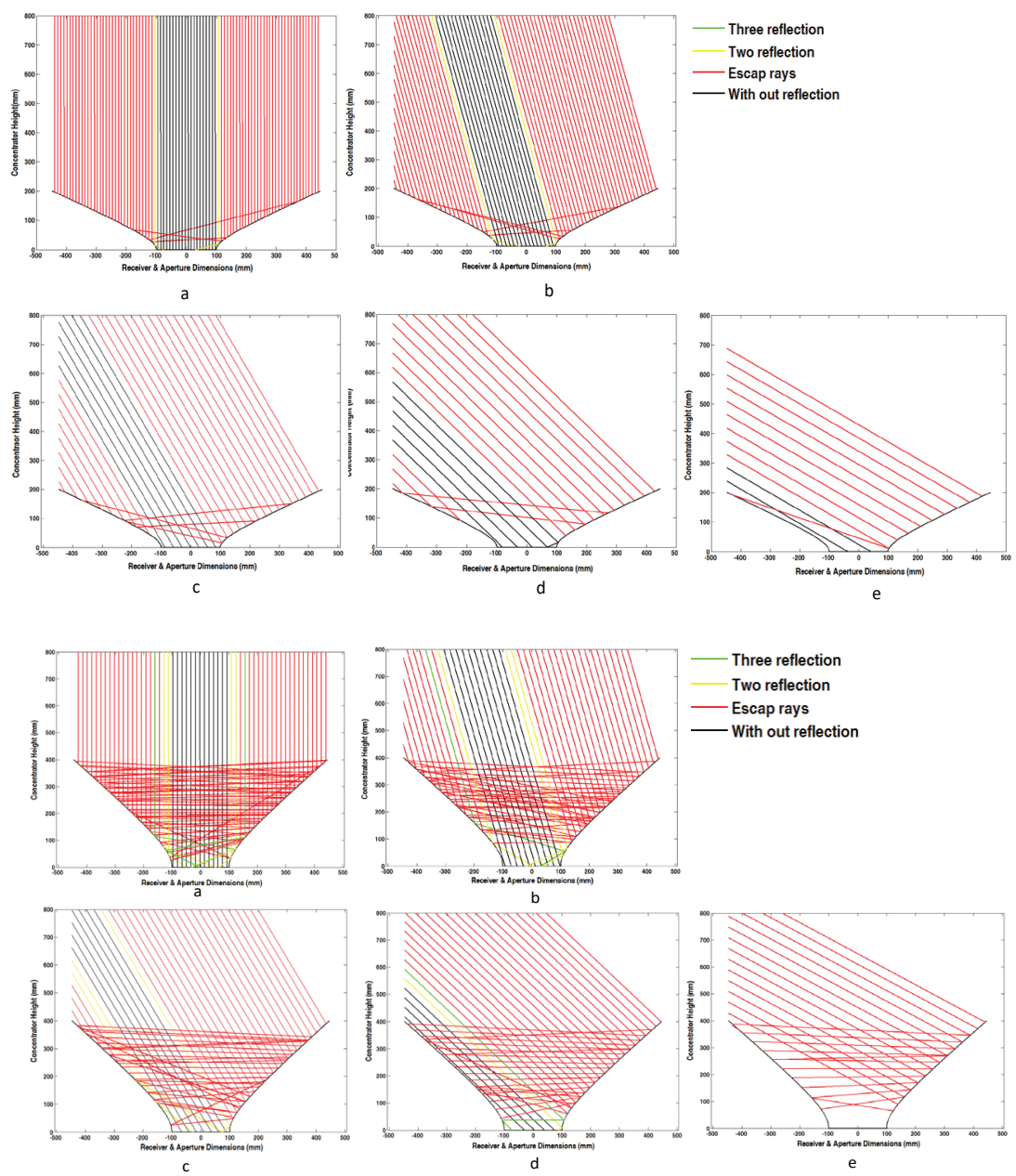

Figure 3: Ray Tracing Diagrams for Concentrator Heights of $0.2 \mathrm{~m}$ (top five) and $0.4 \mathrm{~m}$ (Bottom Five) for Different Incidence Angles (a) $0^{\circ}$, (b) $15^{\circ}$, (c) $30^{\circ}$, (d) $45^{\circ}$ and (e) $60^{\circ}$ 

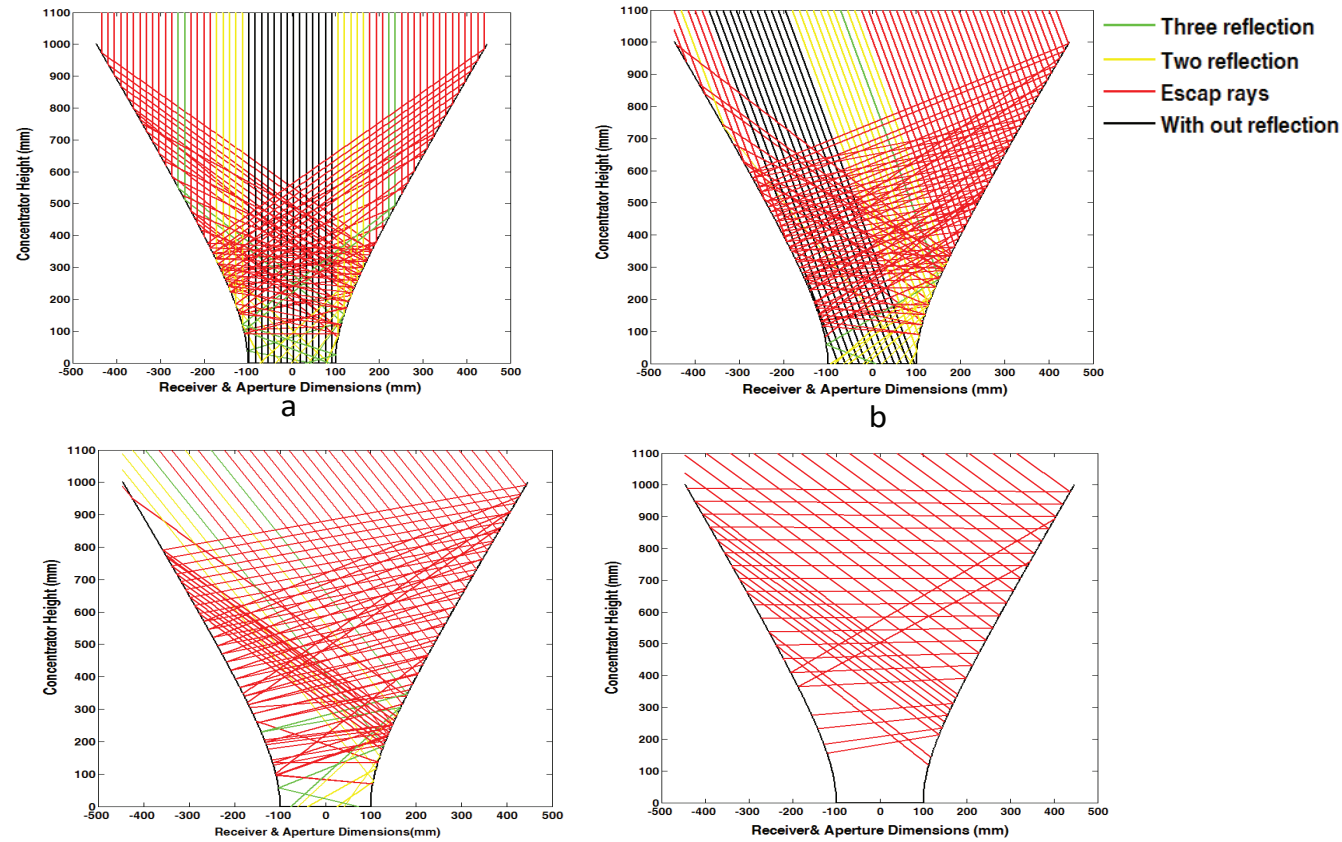

C

d

Figure 4: Ray Tracing Diagrams for Concentrator Heights of $1 \mathrm{~m}$ for Different Incidence Angles (a) $0^{\circ}$, (b) $15,^{\circ}$ (c) $30^{\circ}$ and (d) $45^{\circ}$

The 2-D optical performance of the hyperboloid concentrator is predicted based on the parameters such as geometrical concentration ratio (CRg), geometrical concentrator profile and the height of concentrator (H). The optical efficiency is found based on the ratio of the total number of rays absorbed at the receiver to the total number of rays incident at the aperture of concentrator. In order to predict the optimum configuration of the hyperboloid concentrator, simulations were carried out so that the effect of one parameter (concentrator height) on the optical efficieny is varied and the other parameters are fixed as a constant (area of the concentrator aperture, receiver width).

\section{Optical Efficiency of 2-D Hyperboloid Concentrator (2-D HC)}

The impact of concentration ratio and concentration height on optical efficiency is investigated for different geometrical concentration ratios and concentrator heights. The concentrator height is varied from $0.1 \mathrm{~m}$ to $1.0 \mathrm{~m}$ over the angular range of $\pm 90^{\circ}$ (sun incidence angle). The geometrical concentration ratio is also varied from $5 \times$ to $25 \times$. The variation of optical efficiency for different concentrator heights $(0.1 \mathrm{~m}, 0.2$ $\mathrm{m}, 0.3 \mathrm{~m}, 0.4 \mathrm{~m}, 0.5 \mathrm{~m}, 0.6 \mathrm{~m}, 0.7 \mathrm{~m}, 0.8 \mathrm{~m}, 0.9 \mathrm{~m}, 1 \mathrm{~m})$ and concentration ratios $(5 \times, 10 \times, 15 \times .20 \times$ and $25 \times)$ are shown in figure 5 (from a to e ) receptivity. It is observed that the increase in the concentrator height increases the optical efficiency. The optical efficiency decreases for increasing the concentration ratio. For a fixed concentrator height of $0.4 \mathrm{~m}$, the effect of concentration ratio on optical efficiency is illustrated in Table1. It was found that, at a lower concentration ratio (e.g. $5 \times$ ), the optical efficiency is $51 \%$, and the optical efficiency of $28 \%$ is observed for CR of $10 \times$. Beyond $10 \times(15 \times, 20 \times, 25 \times)$, the variation of optical efficiency is not significant $(15 \%, 14 \%, 12 \%)$ and acceptance angle of $\pm 30^{\circ}$ is observed for the CR of $15 \times, 20 \times, 25 \times$. It is concluded that the hyperboloid concentrator of $20 \times$ can be used to harness large amount of energy over a period during the day with average (not high) optical efficiency and has average energy flux distribution throughout the day. 

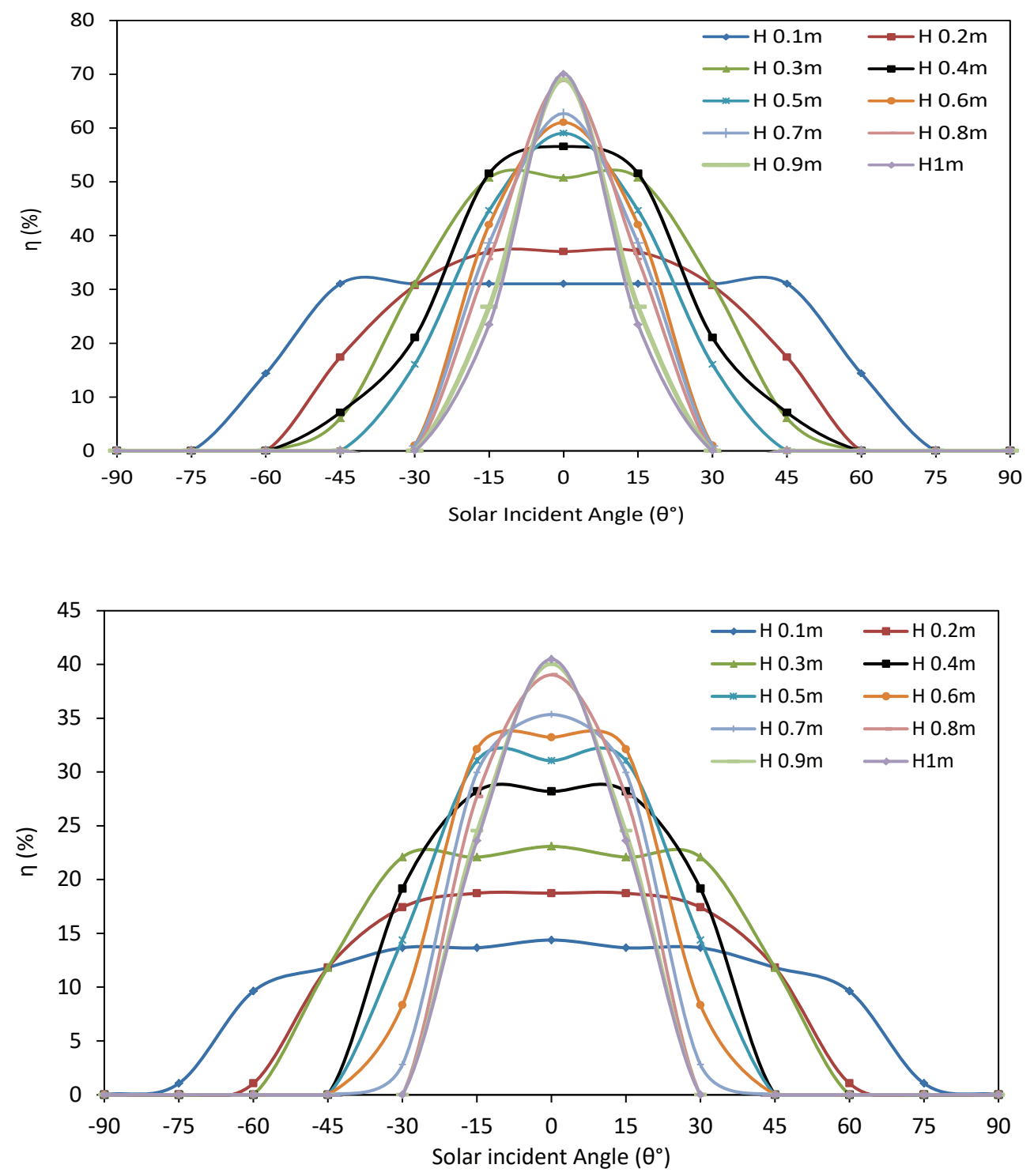

(b) $10 \times$ 


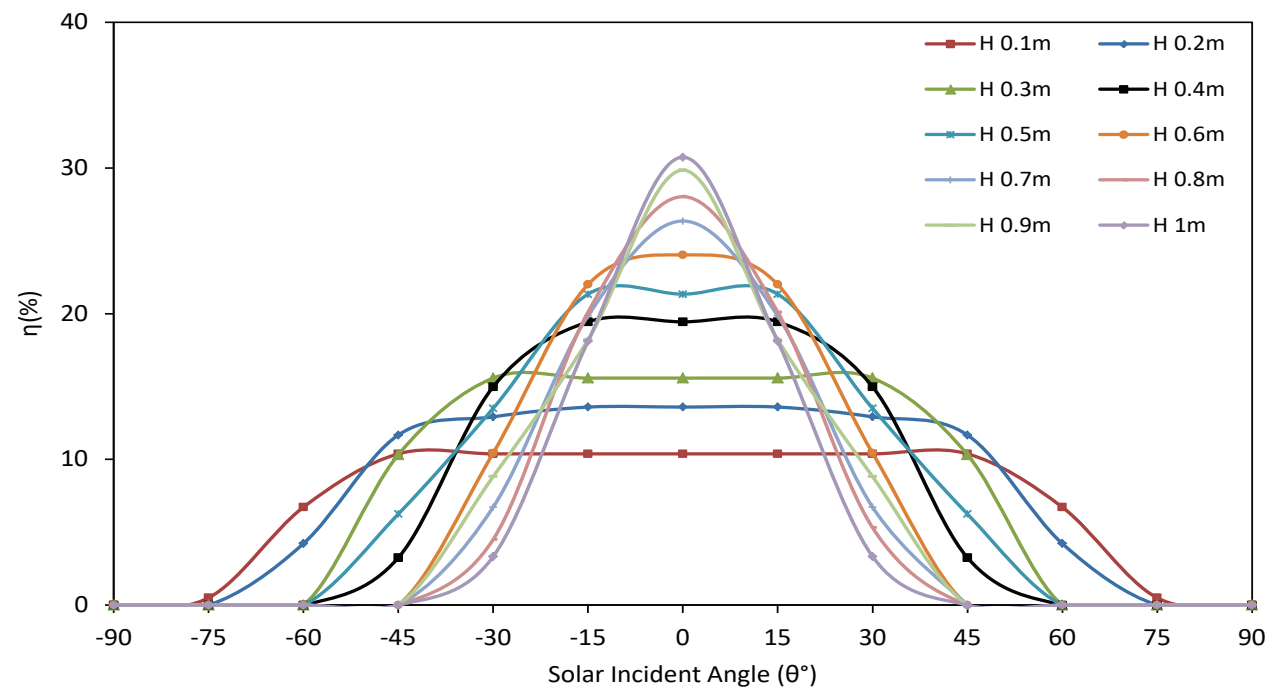

(c) $15 \times$

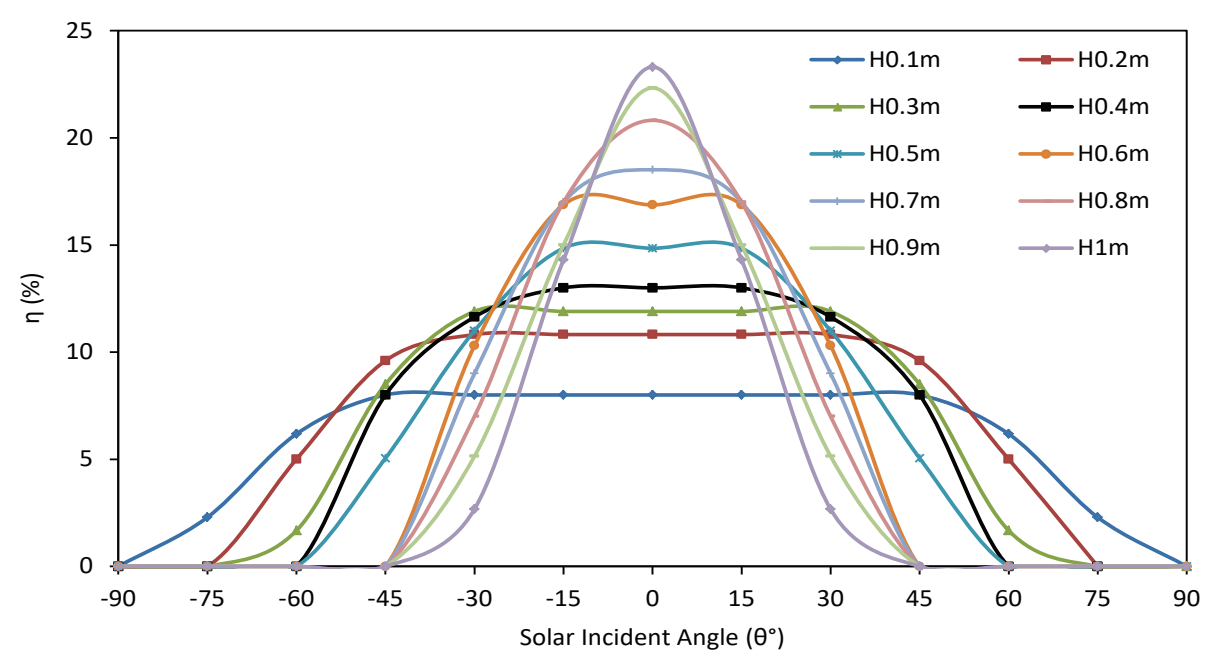

(d) $20 \times$ 


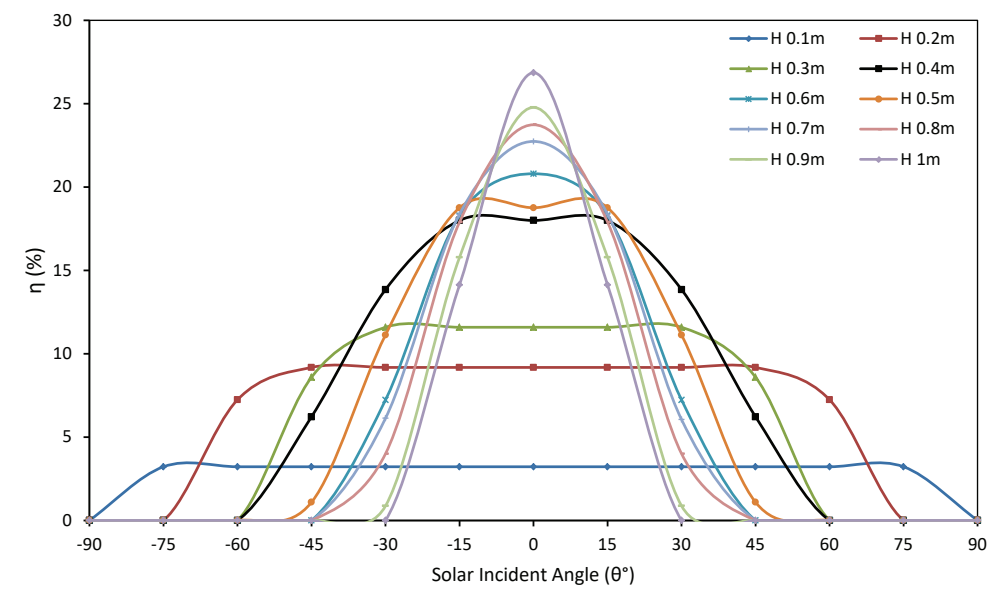

(e) $25 \times$

Figure 3.5: Variation of Optical Efficiency with Solar Incident Angle for 2-D Hyperboloid Concentrator for Different Concentration Ratios (5×,10×, 15×.20× and 25×) and Different Concentrator Heights

\section{Effect of Variation of Receiver diameter on Optical Efficiency}

Ray tracing analysis is carried out for 2-D hyperboloid concentrator of $20 \times$ where the incidence angles are varied from $0^{\circ}$ to $45^{\circ}$. The ray tracing diagram for 2-D hyperboloid concentrator with different receiver diameter for various incidence angles are shown in Figure $\bigotimes 6$. Depending on the total number of rays absorbed at the receiver, compared to the total number of rays incident at the aperture of concentrator, optical efficiency is obtained for the various receiver diameters. The optical efficiency is obtained for a fixed concentration ratio of $20 \times$ and concentrator height of $0.4 \mathrm{~m}$. The receiver diameter is varied from $0.01 \mathrm{~m}$ to $0.1 \mathrm{~m}$. The increase in the receiver diameter, leads to a wider acceptance angle and decreases the optical efficiency. The effect of optical efficiency on the receiver diameter for different solar incidence angle is shown in the figure 7. It is observed the lower receiver diameter leads to a higher optical efficiency and a lower acceptance angle. For higher receiver diameter low optical efficiency and high acceptance angle is observed.
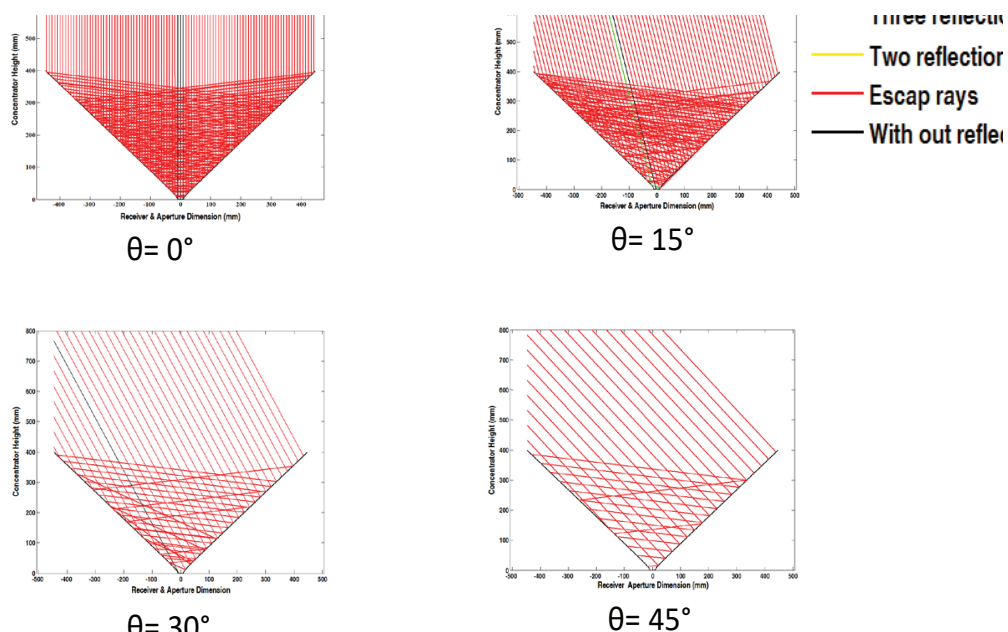

(a) Receiver diameter of $0.05 \mathrm{~m}$ 

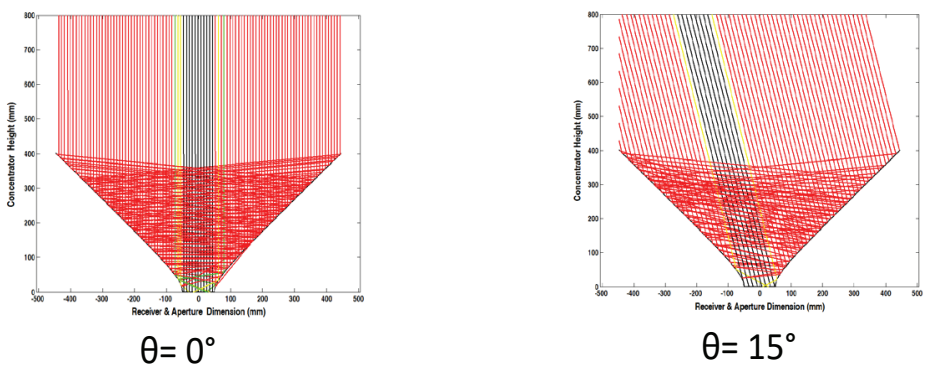

$\theta=15^{\circ}$

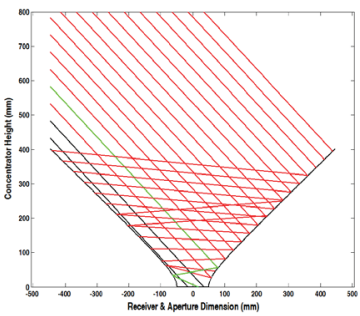

$\theta=30^{\circ}$

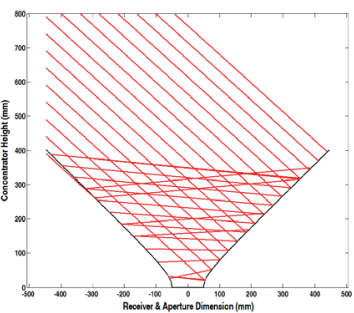

$\theta=45^{\circ}$
Reaches the Receiver

- Three reflection

Two reflection

Escap rays

With out reflection

(b) Receiver diameter of $0.01 \mathrm{~m}$
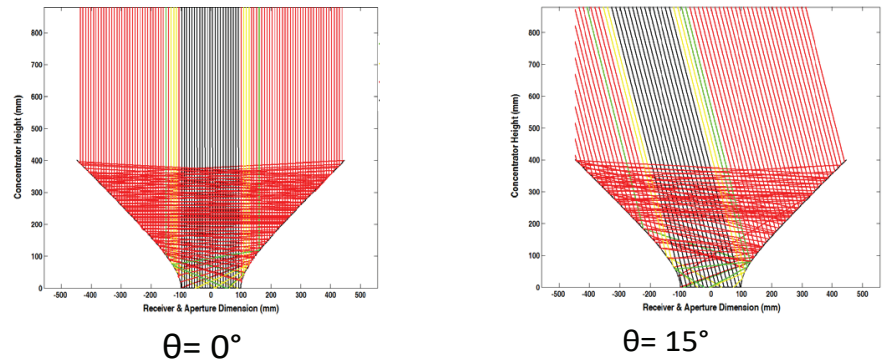

Reaches the Receiver

Three reflection

Two reflection

Escap rays

With out reflection

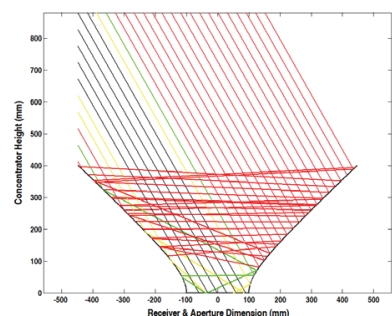

$\theta=30^{\circ}$

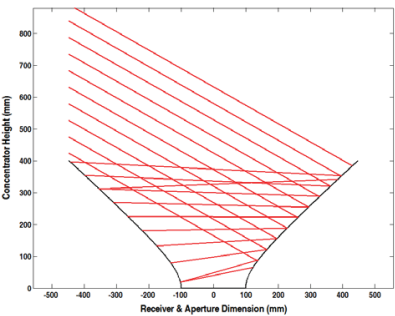

$\theta=45^{\circ}$

(c) Receiver diameter of $0.1 \mathrm{~m}$

Figure 6: Ray tracing diagram for concentration ratio of $20 \times$ based on different receiver diameters ((a) is $0.05 \mathrm{~m},(\mathrm{~b})$ is 0.01 and (c) is $0.1 \mathrm{~m})$ and incidence angles $\left(0^{\circ}, 15^{\circ}, 30^{\circ}\right.$ and $\left.45^{\circ}\right)$ 


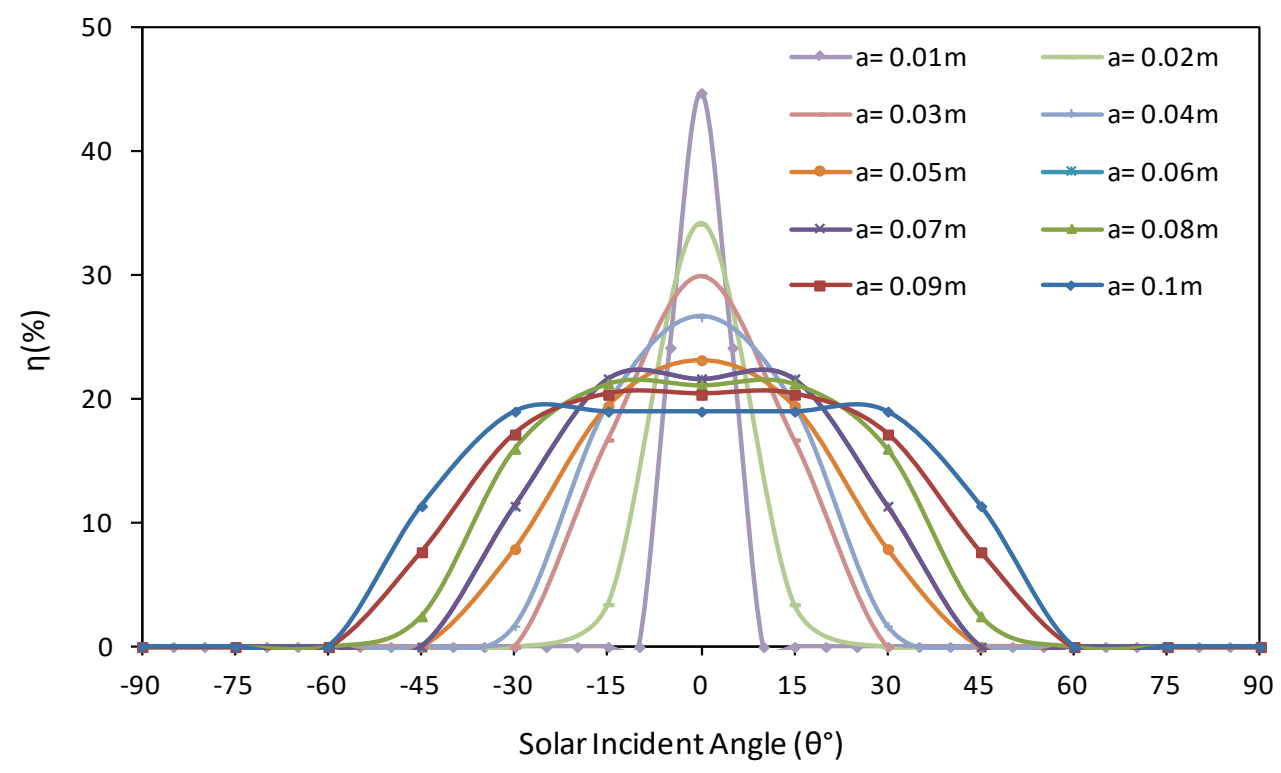

Figure 7: Effect of optical efficiency on the receiver diameter for different solar incidence angles

\section{CONCLUSION}

The performance characterisation of an non-imaging concentrator, a 2-D elliptical hyperboloid concentrator (EHC) for medium temperature process heat applications is investigated. In this investigation, optical and thermal characterisations are extensively carried out for the 2-D static solar concentrator. The 2-D ray tracing simulation code for the elliptical hyperboloid concentrator was developed in MATLAB to predict the optical efficiency of the EHC. and parametric studies such as the effect of acceptance angle; concentration ratio, concentrator height, receiver axis diameter. The 2-D results reveal that there is a possibility of increasing the optical efficiency of the hyperboloid concentrator. Hence, to bring the curvature effects 2-D elliptical hyperboloid concentrator. The optimum configuration is achieved by studying the effects of incidence angle; the height of concentrator and the receiver dimension on the optical efficiency of a 2-D EHC.

\section{REFERENCES}

[1]. E.M.S. Kritchman, K. A. O'Gallagher, J. Winston, R., Stationary nonimaging concentrator as a second stage element in tracking systems, Solar Energy, 30 (1983) 601-602.

[2]. R. Winston, Principles of solar concentrators of a novel design, Solar Energy, 16 (1974) 89-95.

[3]. H. Tabor, Stationary mirror systems for solar collectors, Solar Energy, 2 (1958) 27-33.

[4]. A. Rabl, Comparison of solar concentrators, Solar Energy, 18 (1976) 93-111.

[5]. Garcia-Botella, Angel Fernandez-Balbuena, Antonio Alvarez Vázquez, Daniel Bernabeu, Eusebio, Ideal 3D asymmetric concentrator, Solar Energy, 83 (2009) 113-117.

[6]. Senthilkumar, N. S Yasodha, Design and Development of a Three Dimensional Compound Parabolic Concentrator and Study of Optical and Thermal Performance, International Journal of Energy Science, 2 (2012).

[7]. N. Sellami, T.K. Mallick, D.A. McNeil, Optical characterisation of 3-D static solar concentrator, Energy Conversion and Management, 64 (2012) 579-586.

[8]. I.M. Saleh Ali, Tadhg S.Reddy, K. S. Mallick, Tapas K., An optical analysis of a static 3-D solar concentrator, Solar 
Energy, 88 (2013) 57-70.

[9]. Antonio, Parretta Francesco, Aldegheri Andrea, Antonini Mariangela, Z. Butturi Paolo, Optical simulation of Rondine - PV solar concentrators by two inverse characterization methods, Journal of Optics, 14 (2012) 12570

[10]. I. M. Saleh. Ali, T.K. Malick, P.A Kew, T.S.O'Dononvan, K.S. Reddy, Optical performance evaluation of a 2-D and 3-D novel hyperboloid solar concentrator, in: World Renewable Energy Congress, Abu Dhabi 2010, pp. 1738 -1743. 